\title{
Thermodynamic and kinetic constraints on molecular hydrogen abundance and isotope systematics in hydrothermal fluids
}

\author{
DR. ANDREA RICCI, PHD ${ }^{1}$, JENS FIEBIG ${ }^{2}$, BARBARA I. \\ KLEINE $^{1}$, JÓHANN GUNNARSSON-ROBIN ${ }^{1}$, KENNEDY M. \\ KAMUNYA $^{3}$, BRUCE MOUNTAIN ${ }^{4}$ AND ANDRI \\ STEFÁNSSON ${ }^{1}$ \\ ${ }^{1}$ University of Iceland \\ ${ }^{2}$ Goethe University Frankfurt \\ ${ }^{3}$ Kenya Electricity Generating Company Ltd. \\ ${ }^{4}$ GNS Science \\ Presenting Author: andrearicci@hi.is
}

Molecular hydrogen is one of the major gas constituents in hydrothermal fluids where it plays a pivotal role in geological and biological processes. Nonetheless, factors controlling molecular hydrogen abundance and isotope fractionation remain poorly understood and quantified. We report hydrogen fugacity $\left(f \mathrm{H}_{2}\right)$ and $\delta \mathrm{D}$ of $\mathrm{H}_{2}$ and $\mathrm{H}_{2} \mathrm{O}$ for hydrothermal fluids of variable temperature $\left(226-359{ }^{\circ} \mathrm{C}\right)$ from terrestrial volcanic arc and rift systems sourced by seawater and meteoric water The hydrothermal fluid $f \mathrm{H}_{2}, \delta \mathrm{D}-\mathrm{H}_{2}$ and $\delta \mathrm{D}-\mathrm{H}_{2} \mathrm{O}$ values are of 0.002 3.3 bar, -646 to $-391 \%$ and -94.1 to $+11.3 \%$, respectively. Comparison of dataset with results of geochemical modeling revealed that in meteoric water systems $\mathrm{H}_{2}$ production is controlled by the reduction of $\mathrm{H}_{2} \mathrm{O}$ upon oxidation of aqueous $\mathrm{Fe}^{\mathrm{II}}$ to $\mathrm{Fe}^{\mathrm{III}}$ and subsequent formation of $\mathrm{Fe}$-containing mineral. Elevated sulfur contents, sourced from volcanic gas and/or seawater, result in oxidation of aqueous $\mathrm{S}^{-\mathrm{II}}$ to pyrite and $\mathrm{S}^{+\mathrm{VI}}$, providing a further source of electrons along with $\mathrm{Fe}^{\mathrm{II}}$ oxidation. Our results show that hydrogen fugacity in hydrothermal fluids is controlled by metastable equilibria along a fluid-rock reaction path that primarily depend on temperature, rock-to-water ratio, source water composition and volcanic gas input. The dataset demonstrates that $\delta \mathrm{D}$ ratio of $\mathrm{H}_{2}$ is controlled by the isotopic composition of the source water and equilibrium isotope fractionation at the hydrothermal reservoir temperatures. Upon fluid ascent to surface, $\mathrm{H}_{2}-\mathrm{H}_{2} \mathrm{O}$ isotope exchange re-equilibration may occur, this depends on cooling rate coupled with the kinetics of the isotope fractionation reaction. Based on the extent of hydrogen isotope disequilibrium, we estimate reservoir-tosurface travel times of minutes to $<3$ hours and few hours to days for geothermal wells and fumaroles fluids, respectively. The Project has received funding from the European Union's Horizon 2020 under Grant Agreement \#818169. 